\title{
RESISTANCE OF PROPIONIBACTERIA TO ANTIBIOTICS USED IN THE TREATMENT OF ACNE
}

\author{
JaCQueline M. Brown and Susan M. Poston
}

\section{Department of Microbiology, Guy's Hospital Medical School, London SE1 9RT}

\begin{abstract}
SummaRY. Strains of propionibacteria resistant to clindamycin or clindamycin and erythromycin were isolated from four patients with acne, three of whom were receiving clindamycin. Four strains of $P$. acnes and one of $P$. granulosum with moderate levels of tetracycline resistance were isolated from 25 patients with acne being treated with tetracycline. A similar increase in tetracycline resistance was achieved by training sensitive strains in vitro. $P$. acnes was sensitive to sulphonamide and trimethoprim but some strains of $P$. granulosum were resistant to sulphonamide. Similar reports of clindamycin and erythromycin resistance from the USA suggest resistance may be increasing in isolates from patients with acne.
\end{abstract}

\section{INTRODUCTION}

Antibiotics are used with considerable success in the treatment of patients with acne, although not all respond. The propionibacteria that are part of the normal bacterial flora of the skin, Propionibacterium acnes in particular, have been implicated in the pathogenesis of acne, especially in the inflammatory stages of the disease (Marples, Downing and Kligman, 1971; Cunliffe et al., 1981; Holland, Ingham and Cunliffe, 1981).

Treatment with antibiotics may reduce the number of propionibacteria and this correlates with reduced levels of free fatty acids and reduction in the severity of disease. Treatment with tetracycline or minocycline by mouth in normal therapeutic doses reduced the numbers of $P$. acnes in skin washings and was accompanied by clinical improvement (Marples and Kligman, 1971; Leyden, McGinley and Kligman, 1982). However, clinical improvement, with a fall in free fatty acid levels (Cunliffe et al., 1973) but without reduction in bacterial numbers, also occurred in patients with mild or moderate acne on low-dose tetracycline therapy, which suggests that inhibition of lipase activity that is responsible for the production of free fatty acids (Marples et al., 1971) rather than reduction of bacterial numbers was an important factor in successful therapy (Cove, Cunliffe and Holland, 1980). A marked fall in numbers of $P$. acnes in comedones occurred with clindamycin but not erythromycin therapy although there was clinical improvement with both agents (Resh and Stoughton, 1976; Stoughton, 1979). 
Studies of antibiotic sensitivity of large numbers of propionibacteria have indicated that this group of organisms is generally sensitive to a wide range of antibacterial agents, including those used for acne therapy (Martin, Gardner and Washington, 1972; Chow, Patten and Guze, 1975; Tally et al., 1975; Wang et al., 1977; Hoffler, Niederau and Pulverer, 1980). This contrasts with the sensitivity of coagulase-negative staphylococci on the skin that are often resistant to one or more antibiotics (Corse and Williams, 1968). Some isolates of $P$. acnes have slightly raised levels of resistance to tetracycline compared with the majority (Chow et al., 1975) and Gould and Cunliffe (1978) reported the isolation of tetracycline-resistant strains during clinical treatment although the total number isolated over a 10-year period was small. Recently, reports from the USA have indicated that clindamycin- and erythromycin-resistant strains can be isolated from patients undergoing therapy. Crawford et al. (1979) isolated clindamycin- and erythromycin-resistant strains of $P$. acnes from comedones of about $20 \%$ of patients who were using topical lotions containing $1 \%(\mathrm{w} / \mathrm{v})$ of either drug. Resistant strains (MIC $>25 \mu \mathrm{g} / \mathrm{ml}$ ) have also been isolated from previously untreated acne patients (Guin, Huber and Gierlerak, 1979) including one strain of P. granulosum resistant to tetracycline, erythromycin and clindamycin and a strain of $P$. acnes resistant to tetracycline.

We have looked for resistant strains of propionibacteria in patients undergoing antibiotic therapy for acne and in some individuals without acne. Patients had been on antibiotic therapy for 4 months or more and, as far as possible, were those who had not responded well to therapy. It was assumed that resistant strains might be found in this group of patients.

\section{MATERIALS AND METHODS}

Bacterial strains. A total of 253 strains of propionibacteria were isolated from 69 subjects (table I). The 28 patients receiving antibiotic therapy included 20 patients attending the Dermatology Clinic at Guy's Hospital and eight patients from St John's Hospital. Swabs from the patients at St John's Hospital were kindly provided by Dr W. C. Noble. Strains isolated from children were provided by Ms K. Nördstrom, Institute of Dermatology, London. P. acnes NCTC737 was used as a reference strain.

Media. Blood agar (BA) plates (Tissue Culture Services) were used routinely for cultures. Peptone-yeast-glucose medium with cysteine $0.1 \%(\mathrm{w} / \mathrm{v})$ as a reducing agent and adjusted to $p \mathrm{H}$ 6.9 (PYGC), was used as broth or solidified with agar (Oxoid no. 1 or New Zealand agar, $1 \%$ $w / v)$. Carbohydrate media for fermentation tests were PYGC containing $1 \%(w / v)$ of the

TABLE I

Identity and source of strains of propionibacteria tested for antibiotic sensitivity

\begin{tabular}{|c|c|c|c|c|c|}
\hline \multirow{2}{*}{$\begin{array}{l}\text { Group of } \\
\text { subjects }\end{array}$} & \multirow{2}{*}{$\begin{array}{l}\text { Number of } \\
\text { subjects }\end{array}$} & \multicolumn{4}{|c|}{ Number of strains isolated and tested } \\
\hline & & P. acnes & P. granulosum & P. avidum & Total \\
\hline $\begin{array}{l}\text { Acne patients on } \\
\text { antibiotic therapy } \\
\text { Acne patients }\end{array}$ & 28 & 165 & 7 & 4 & 176 \\
\hline $\begin{array}{l}\text { untreated } \\
\text { Non-acne patients }\end{array}$ & $\begin{array}{r}2 \\
10\end{array}$ & $\begin{array}{r}7 \\
31\end{array}$ & $\begin{array}{l}1 \\
5\end{array}$ & $\begin{array}{l}\mathbf{0} \\
\mathbf{0}\end{array}$ & $\begin{array}{r}8 \\
36\end{array}$ \\
\hline $\begin{array}{l}\text { Normal children } \\
\text { Total }\end{array}$ & $\begin{array}{l}29 \\
69\end{array}$ & $\dddot{203}$ & $\dddot{13}$ & $\dddot{4}$ & $\begin{array}{r}33 \\
253\end{array}$ \\
\hline
\end{tabular}


carbohydrate in $10 \mathrm{ml}$-volumes in standard test tubes to a depth of about $6.5 \mathrm{~cm}$. PYGC and media for fermentation tests were based on the Anaerobe Laboratory Manual (Holdeman and Moore, 1972). Plates were incubated in an anaerobic jar (Gaz Kit, Oxoid). Liquid cultures containing cysteine were incubated aerobically unless otherwise stated. DSTA (Tissue Culture Services) was used for disk sensitivity tests and DST (Oxoid) agar or PYGC for MIC tests.

Sampling methods. Skin washings of the forehead or back were taken with a glass cylinder (34 mm diameter) held against the skin (Williamson and Kligman, 1965); $2 \mathrm{ml}$ of Triton X-100 $0.1 \%$ in $0.1 \mathrm{M}$ phosphate buffer $(\mathrm{pH} 7.9)$ were introduced and the skin surface rubbed for $1 \mathrm{~min}$ with a teflon rod with a flattened end. The fluid was removed, the procedure repeated and the two samples pooled. Samples were plated on non-selective medium and incubated anaerobically for $4-5$ days at $37^{\circ} \mathrm{C}$.

Identification. After three single-colony sub-cultures for purification, propionibacteria were recognised as characteristic gram-positive rods that failed to grow aerobically on blood agar. Strains were identified as $P$. acnes, $P$. granulosum or $P$. avidum on the basis of the following tests: acid from glucose, sucrose, maltose or sorbitol, aesculin hydrolysis, indole production, nitrate reduction and gelatin liquefaction (Cummins and Johnson, 1974). $P$. acnes isolates were agglutinated by Corynebacterium acnes antiserum No. 554 (Difco).

Storage. Bacteria were maintained on nutrient medium under anaerobic conditions. Strains were stored on glass beads at $-70^{\circ} \mathrm{C}$ (Feltham et al., 1978) as follows: 3-5-day cultures were emulsified in PYGC broth containing glycerol $10 \%(\mathrm{w} / \mathrm{v})$ to give a dense suspension of $c .10^{9}$ $\mathrm{cfu} / \mathrm{ml}$. A small volume was used to moisten the surface of several glass beads in a screw-capped glass vial. Excess culture suspension was removed and the vials stored at $-70^{\circ} \mathrm{C}$. Each bead carried about $10^{6}$ bacteria and viability was well maintained for the 18-month test period. Viable counts showed a fall of about 10 -fold in this time.

Determination of minimum inhibitory concentrations. Doubling dilutions of tetracycline, erythromycin (supplied by Lilly Research Laboratories) or clindamycin were made in PYGC agar and of sulphamethoxazole or trimethoprim in DST agar. Antibiotic-containing media were inoculated with a multiple inoculator loaded with a 48-h liquid culture diluted 1 in 1000 in saline to give semi-confluent growth on the antibiotic-free control plates. Lysed horse blood $(5-7 \%)$ was added to DST agar. Plates were incubated for 4 days at $37^{\circ} \mathrm{C}$. The MIC was the concentration that gave a greater than 50-fold reduction in growth compared with the control plate, or complete inhibition of growth; the latter was the most common end-point. Erythromycin and clindamycin were dissolved and diluted in ethyl alcohol; other antibiotics were dissolved in distilled water. The range of concentrations was $0.048-100 \mu \mathrm{g} / \mathrm{ml}$. P. acnes NCTC737 was included as a standard sensitive strain in each series of tests. Occasionally MIC values varied by two-fold in tests on different occasions; with sulphamethoxazole and trimethoprim the variation was as much as four-fold.

Training experiments. Volumes $(0.5 \mathrm{ml})$ of 2-day PYGC cultures were inoculated into a series of tubes of arithmetic or doubling dilutions of antibiotic and incubated for 5-7 days at $37^{\circ} \mathrm{C}$. Volumes of $0.5 \mathrm{ml}$ from tubes containing the highest concentration of antibiotic that allowed greater than $50 \%$ growth when compared visually with the control, were inoculated into a further series of antibiotic-containing media. When there appeared to be an increase in resistance of the culture, MIC determinations were made directly from 1000-fold dilutions of cultures. Cultures were checked for purity and tested for growth in anaerobic but not aerobic conditions on blood agar, colonial appearance and antibiotic-sensitivity pattern.

\section{RESULTS}

Up to 10 colonies of propionibacteria were isolated from washings taken from patients and tested for antibiotic sensitivity. It is possible that all the isolates from an individual were of the same strain because the tests used for identification did not distinguish between strains of a species. Antibiotic sensitivity tests showed some differences in resistance between individual isolates from the same patient; therefore, several colonies from each patient were screened. MIC determinations were 
performed on all isolates. With a few exceptions, most strains were sensitive to the five antibiotics tested (table 2). The 33 strains of propionibacteria isolated from children were all sensitive to the five antibiotics.

\section{Tetracycline and minocycline sensitivity}

Some strains of $P$. acnes and $P$. granulosum showed a small but reproducible increase in level of resistance (MIC $3 \cdot 1 \mu \mathrm{g} / \mathrm{ml}$ ) to tetracycline (table II). These strains were isolated from patients who had been treated with tetracycline for 4 months or longer with the exception of one patient who had received tetracycline therapy intermittently.

Moderately resistant strains of $P$. acnes were isolated from four such patients and of $P$. granulosum from one. However, strains with increased resistance were not isolated from the remaining 20 patients receiving similar courses of tetracycline. Tetracycline-resistant strains were not found amongst 77 strains of propionibacteria from 12 adults and 29 children who were not receiving therapy.

Attempts were made to increase the level of tetracycline resistance of moderately resistant or sensitive strains by successive culture in liquid medium containing tetracycline. With strains showing moderate levels of tetracycline resistance, very little or no increase in resistance was achieved after nine sub-cultures, but the MIC of normally-sensitive strains (MIC 0.39-0.78 $\mu \mathrm{g} / \mathrm{ml}$ ) could be increased to $6.25 \mu \mathrm{g} / \mathrm{ml}$ by similar passage. It was also observed that strains were able to grow in liquid medium with concentrations of tetracycline about four-fold higher than would be expected from their MIC in solid media. When MIC tests in liquid culture were incubated under anaerobic conditions the MIC values were very similar to those obtained under aerobic conditions (table III).

MIC's of minocycline were about four-fold lower than tetracycline MIC values

\section{TABLE II}

Minimum inhibitory concentration of antibiotics for strains of propionibacteria isolated from subjects with and without acne

\begin{tabular}{|c|c|c|c|c|c|}
\hline \multirow[b]{2}{*}{ Antibiotic } & \multirow[b]{2}{*}{$\underset{(\mu \mathrm{g} / \mathrm{ml})}{\mathrm{MIC}}$} & \multicolumn{3}{|c|}{$\begin{array}{l}\text { Number of test strains with the given } \\
\text { MIC }\end{array}$} & \multirow[b]{2}{*}{$\begin{array}{c}\text { MIC for reference } \\
\text { strain } P . \text { acnes } \text { NCTC737 }\end{array}$} \\
\hline & & $\begin{array}{l}\text { P. acnes } \\
(\mathrm{n}=203)\end{array}$ & $\begin{array}{l}P . \text { granulosum } \\
(\mathrm{n}=13)\end{array}$ & $\begin{array}{l}\text { P. avidum } \\
(\mathrm{n}=4)\end{array}$ & \\
\hline Tetracycline & $\begin{array}{l}0.39-0.78 \\
3 \cdot 12\end{array}$ & $\begin{array}{r}179 \\
24\end{array}$ & $\begin{array}{l}8 \\
5\end{array}$ & 4 & $0.39-0.78$ \\
\hline Clindamycin & $\begin{array}{c}<0.048-0.097 \\
0.39 \\
6.25 \\
>100.00\end{array}$ & $\begin{array}{r}184 \\
4 \\
4 \\
11\end{array}$ & 11 & 4 & $0.048-0.097$ \\
\hline Erythromycin & $\begin{array}{l}\gtrless 0.048-0.097 \\
>100.0\end{array}$ & $\begin{array}{r}11 \\
11\end{array}$ & $\begin{array}{r}2 \\
21\end{array}$ & 4 & $0.048-0.097$ \\
\hline Sulphamethoxazole & $\begin{array}{l}0 \cdot 78-3 \cdot 12 \\
6 \cdot 25-12 \cdot 5 \\
>100 \cdot 0\end{array}$ & 201 & $\begin{array}{l}6 \\
7\end{array}$ & 4 & $0.78-3 \cdot 12$ \\
\hline Trimethoprim & $\begin{array}{l}0.39-1.56 \\
0.78-3.12\end{array}$ & 201 & 13 & 4 & $0.39-1.56$ \\
\hline
\end{tabular}


TABLE III

Minimum inhibitory concentrations of tetracycline for three test strains in aerobic and anaerobic conditions of incubation

\begin{tabular}{|c|c|c|c|}
\hline \multirow[b]{3}{*}{ Strain } & \multicolumn{3}{|c|}{$\begin{array}{l}\text { MIC of tetracycline }(\mu \mathrm{g} / \mathrm{ml}) \text { for the } \\
\text { given strain }\end{array}$} \\
\hline & \multicolumn{2}{|c|}{ in broth with } & \multirow{2}{*}{$\begin{array}{c}\text { in agar with } \\
\text { anaerobic } \\
\text { incubation }\end{array}$} \\
\hline & $\begin{array}{l}\text { aerobic } \\
\text { incubation }\end{array}$ & $\begin{array}{l}\text { anaerobic } \\
\text { incubation }\end{array}$ & \\
\hline $\begin{array}{l}\text { P. acnes } \text { NCTC737 Tet* Sm } \ddagger \\
\text { P. acnes Tet } \dagger \\
P \text {. acnes } \text { NCTC737 Sm } \ddagger\end{array}$ & $\begin{array}{c}25 \cdot 0 \\
25 \cdot 0 \\
3 \cdot 12\end{array}$ & $\begin{array}{l}6 \cdot 25 \\
3 \cdot 12 \\
1 \cdot 56\end{array}$ & $\begin{array}{c}6 \cdot 25 \\
3 \cdot 12 \\
0 \cdot 78-1 \cdot 56\end{array}$ \\
\hline
\end{tabular}

* After passage through tetracycline-containing broth.

$\dagger$ Tetracycline-resistant clinical isolate.

$\ddagger$ High-level streptomycin-resistant mutant.

with 17 strains of $P$. acnes and two strains of $P$. granulosum with low or moderate sensitivity to tetracycline. Strains with a tetracycline MIC of $0.39-0.78 \mu \mathrm{g} / \mathrm{ml} \mathrm{had}$ minocycline MIC's of $0.097-0.195 \mu \mathrm{g} / \mathrm{ml}$ and strains with a tetracycline MIC of 3.12 $\mu \mathrm{g} / \mathrm{ml}$ had minocycline MIC's of $0.78 \mu \mathrm{g} / \mathrm{ml}$.

\section{Clindamycin and erythromycin sensitivity}

Clindamycin-resistant strains were isolated from four of the 28 patients studied (table IV). Three had been receiving clindamycin therapy, one topically and two orally, for 4 months or more. The fourth patient was not known to have been treated with clindamycin or erythromycin. The four strains isolated from the patient who was using a topical preparation of clindamycin $1 \%(\mathrm{w} / \mathrm{v})$ showed moderate resistance to clindamycin (MIC $6.25 \mu \mathrm{g} / \mathrm{ml}$ ) but were sensitive to erythromycin. Ten strains of $P$. acnes isolated from one patient on oral clindamycin therapy were resistant to clindamycin and erythromycin (MIC $>100 \mu \mathrm{g} / \mathrm{ml}$ ) and were moderately resistant to tetracycline (MIC $3.12 \mu \mathrm{g} / \mathrm{ml}$ ). From the third patient on clindamycin therapy, two strains resistant to clindamycin and erythromycin were isolated. These were identified as atypical strains of $P$. granulosum that did not ferment maltose or sucrose. Only one of eight strains of $P$. acnes isolated from the fourth patient, who was receiving oral tetracycline therapy, was resistant to clindamycin and erythromycin (MIC $>100$ $\mu \mathrm{g} / \mathrm{ml})$.

\section{Sulphamethoxazole and trimethoprim sensitivity}

All the isolates of $P$. acnes tested were sensitive to sulphamethoxazole and trimethoprim independently (table II). However, isolates of $\boldsymbol{P}$. granulosum and $\boldsymbol{P}$. avidum from subjects with or without acne had increased resistance to sulphamethoxazole (MIC $6 \cdot 25-12.5 \mu \mathrm{g} / \mathrm{ml}$ ) and some strains of $P$. granulosum were fully resistant (MIC $>100 \mu \mathrm{g} / \mathrm{ml}$ ) (table II). Synergy was demonstrated with both sulphamethoxazole-sensitive and -resistant strains when combinations of sulphamethoxazole and 


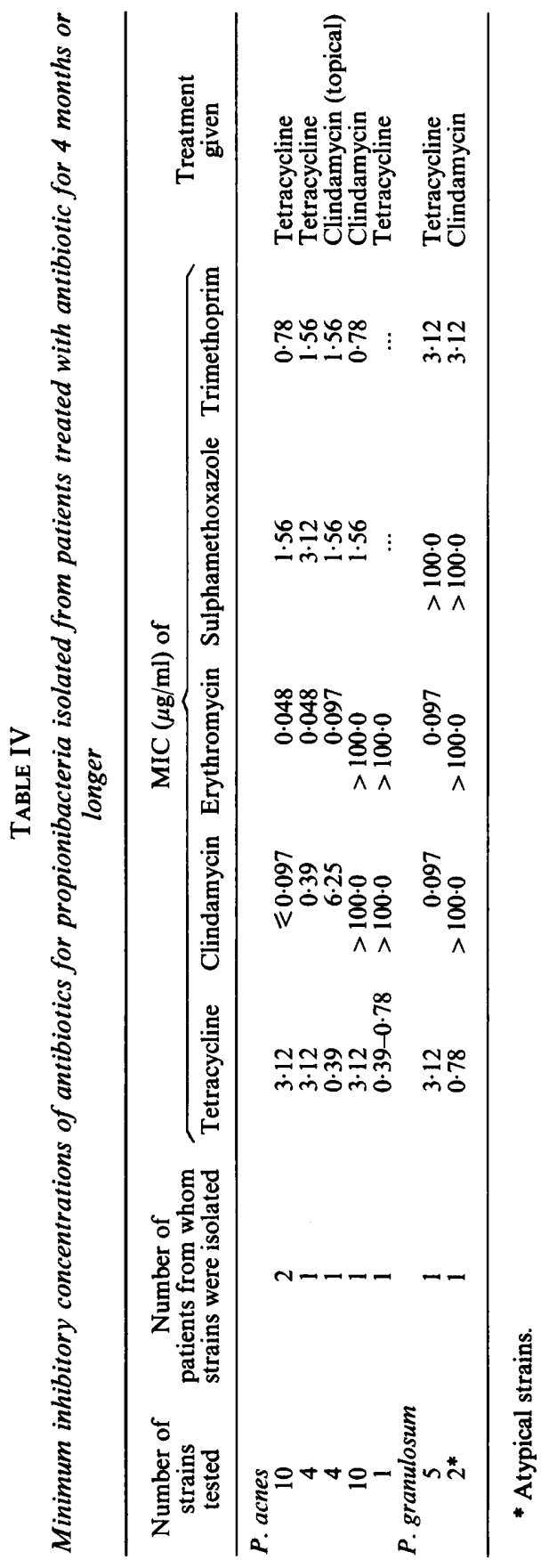


trimethoprim in ratios of 2-32:1 were used in plate MIC tests. Synergy was also demonstrated in disk tests.

\section{DisCUSSION}

Tetracycline and several other antibiotics are effective in the treatment of acne. Oral clindamycin was introduced in the early 1970's, followed by topical preparations of clindamycin, erythromycin and tetracycline (Resh and Stoughton, 1976; Stoughton, 1979; Adams, Cooke and Cunliffe, 1981). Several studies have established the efficacy of these topical preparations, particularly clindamycin (Resh and Stoughton, 1976; Adams et al., 1981) which is used extensively in the USA (Stoughton, 1979). However, in view of the association between topical and oral therapy with clindamycin and antibiotic-associated pseudomembranous colitis (Cohen, McNeill and Wells, 1973; Milstone, McDonald and Scholhamer, 1981), care in its use is indicated (Adams et al., 1981). The relatively small number of patients being treated with clindamycin in this study reflects the conservative use of this drug.

Less significance is now attributed to the direct role of free fatty acids in the inflammatory reaction in acne (Puhvel and Sakamoto, 1977; Webster, McGinley and Leyden, 1981). This view is supported by the evidence of Weeks et al. (1977) who showed that topical application of potent inhibitors of bacterial lipase did not alleviate the severity of acne lesions although they rapidly reduced free fatty acid levels. However, some of the products of comedonal bacteria act as chemotactic agents (Puhvel and Sakamoto, 1980). The lipase of $P$. acnes is chemotactic for human polymorphonuclear leucocytes (Lee et al., 1982) and hyaluronidase and phosphatase are chemotactic for monocytes (Gould et al., 1979). Some substances are directly chemotactic and with others complement is involved. A possible mechanism for antibiotic action was proposed for tetracycline which has been shown to inhibit lipase activity in P. acnes (Hassing, 1971; Weaber, Freedman and Eudy, 1971; Marples et al., 1971; Cove et al., 1980). Production of lipase was delayed at concentrations of tetracycline that had little effect on growth (Webster et al., 1981; Unkles and Gemmell, 1982) and a similar effect was produced by erythromycin (Webster et al., 1981). Tetracycline inhibited lipase production to a greater extent in $P$. granulosum, whereas clindamycin inhibited lipase production by $P$. acnes and $P$. granulosum at concentrations sub-inhibitory for growth (Unkles and Gemmell, 1982).

Some antibiotics have been shown to act directly as anti-inflammatory agents. Clindamycin, erythromycin and tetracycline inhibit chemotaxis of human leukocytes at concentrations below therapeutic blood levels (Esterly, Furey and Flanagan, 1978). There is very little information on the antibiotic concentrations attained in comedonal material although therapeutic concentrations of clindamycin are achieved in some people using topical application of clindamycin (Guin et al., 1979). Smith and Waterworth (1961) could not detect inhibitory activity attributable to tetracycline in comedonal material from patients on tetracycline therapy. Therapeutic levels are reached on the skin surface within 4-8 days with normal doses but they are not always detectable in patients on low-dose regimes (Rashleigh, Rife and Goltz, 1967).

Response to antimicrobial chemotherapy is sometimes slow and fails to alleviate the symptoms in some patients (Leyden, 1976; Gould and Cunliffe, 1978). A number of unrelated factors that might contribute to failure of therapy have been considered, 
including antibiotic resistance in propionibacteria (Leyden, 1976; Cunliffe et al., 1981) but because resistance was not commonly observed it seemed unlikely to be an important cause of treatment failure (Leyden, 1976). However, Crawford et al. (1979) found a substantial incidence of resistance in propionibacteria isolated from patients on topical erythromycin or clindamycin after treatment for 8 weeks or longer; strains were resistant to both drugs. Phenotypically similar strains were derived from sensitive strains in vitro but the genetic basis of their resistance was not necessarily similar (Crawford et al., 1979). The present results confirm that such strains can be isolated from patients on oral clindamycin therapy. The isolation of a resistant strain of $P$. acnes in the absence of clindamycin or erythromycin therapy is similar to the isolation of a resistant strain of $P$. granulosum by Guin et al. (1979) before the start of antibiotic therapy. Other workers have failed to isolate resistant strains from patients receiving therapy. In some studies, the absence of resistance may have been a result of the relatively short period of observation (Bernstein and Shalita, 1980) but in studies over longer periods this is unlikely to account for the absence of resistant strains (Leyden, 1976; Cunliffe et al., 1981).

In spite of the extensive use of tetracycline for acne therapy there is a low incidence of resistance. The MIC values reported here confirm those obtained in other studies, where few strains with an MIC $>6.25 \mu \mathrm{g} / \mathrm{ml}$ have been isolated and most were inhibited at lower concentrations. The greater sensitivity of strains to minocycline compared with tetracycline (Chow et al., 1975; Hoeffler, Ko and Pulverer, 1976) was also confirmed. In contrast with the generally low levels of tetracycline resistance, the strains of $P$. acnes isolated by Guin et al. (1979) with MIC values $>25 \mu \mathrm{g} / \mathrm{ml}$ are of interest. Moreover, they reported a strain resistant to ampicillin (MIC $>25 \mu \mathrm{g} / \mathrm{ml}$ ).

The results of sulphonamide sensitivity tests did not confirm the finding of Hoeffler et al. (1976) that all strains of $P$. acnes were resistant to sulphamethoxazole (MIC $>100 \mu \mathrm{g} / \mathrm{ml}$ ). The isolates of $P$. acnes in this study were uniformly sensitive (MIC $0.78-3.12 \mu \mathrm{g} / \mathrm{ml}$ ) but several strains of $P$. granulosum were resistant (MIC $>100$ $\mu \mathrm{g} / \mathrm{ml})$.

Antibiotic therapy has the disadvantage of selecting a resistant bacterial flora and it has been suggested that this is more likely to occur with the topical use of drugs (Noble, 1981). The source of resistant strains isolated from these patients is not known, but there are a number of possibilities. These include reinfection or recolonisation of the skin by resistant strains from another source after reduction of the sensitive flora or selection of resistant cells from the original population. Antibiotic resistance may be determined by plasmid or chromosomal genes. Clindamycin-resistant mutants can be isolated in vitro (Crawford et al., 1979; Brown, unpublished observations) and chromosomal mutations could, therefore, account for resistant strains, particularly in patients undergoing long-term antibiotic therapy. The effect of bacterial resistance on the outcome of antibiotic therapy is not known but must be considered in studies of the response to therapy because it seems likely that the incidence of resistance will increase with the use of these antimicrobial agents.

We are grateful to Dr D. M. MacDonald, Dermatology Department, Guy's Hospital, for access to his patients and to the patients for their co-operation. J.M.B. was supported by a grant from the Special Trustees, Guy's Hospital. 


\section{REFERENCES}

Adams, S. J., CoOKe, E. M. AND CUNLIFFe, W. J. 1981. The use of oral and topical antibiotics in acne. Journal of Antimicrobial Chemotherapy 7, suppl. A75-80.

Bernstein, J. E. and Shalita, A. R. 1980. Effects of topical erythromycin on aerobic and anaerobic surface flora. Acta Dermatovener (Stockholm) 60, 537-539.

Chow, A. W., Patten, V. and Guze, L. G. 1975. Comparative susceptibility of anaerobic bacteria to minocycline, doxycycline and tetracycline. Antimicrobial Agents and Chemotherapy, 7, 46-49.

CohEn, L. E., MCNeIll, C. J. AND Wells, R. F. 1973. Clindamycin associated colitis. Journal of the American Medical Association, 223, 1379-80.

Corse, J. AND Williams, R. E. O. 1968. Antibiotic resistance of coagulase-negative staphylococci and micrococci. Journal of Clinical Pathology, 21, 722-728.

Cove, J. H., Cunliffe, W. J. and Holland, K. T. 1980. Acne vulgaris: is the bacterial population size significant. British Journal of Dermatology, 102, 277-280.

Crawford, W. W., Crawford, I. P., Stoughton, R. B. and Cornell, R. C. 1979. Laboratory induction and clinical occurrence of combined clindamycin and erythromycin resistance in Corynebacterium acnes. Journal of Investigative Dermatology, 72, 187-190.

Cummins, C. S. AND Johnson, J. L. 1974. Corynebacterium parvum: a synonym for Propionibacterium acnes? Journal of General Microbiology, 80, 433-442.

Cunliffe, W. J., Clayden, A. D., Gould, D. and Simpson, N. B. 1981. Acne vulgaris-its aetiology and treatment. A review. Clinical and Experimental Dermatology, 6, 461-469.

Cunliffe, W. J., Forster, R. A., Greenwood, N. D., Hetherington, C., Holland, K. T., Holmes, R. L., Khan, S., Roberts, C. D., Williams, M. and Williamson, B. 1973. Tetracycline and acne vulgaris: a clinical and laboratory investigation. British Medical Journal, 4, 332-335.

Esterly, N. B., Furey, N. L. AND Flanagan, L. E. 1978. The effect of antimicrobial agents on leukocyte chemotaxis. Journal of Investigative Dermatology, 70, 51-55.

Feltham, R. K. A., Power, A. K., Pell, P. A. and Sneath, P. H. A. 1978. A simple method for storage of bacteria at $-76^{\circ} \mathrm{C}$. Journal of Applied Bacteriology, 44, 313-316.

Gould, D. J. AND CunLIFFE, W. J. 1978. The long term treatment of acne vulgaris. Clinical and Experimental Dermatology, 3, 249-252.

Gould, D. J., Ingham, E., Gowland, G. ANd Cunliffe, W. J. 1979. Leucocyte chemotaxis in acne vulgaris: the role played by $P$. acnes and host factors. British Journal of Dermatology, 101, $104-105$.

Guin, J. D., Huber, D. S. AND GierleraK, P. L. 1979. Antibiotic sensitivity of comedonal Propionibacterium acnes. Acta Dermato-Venereologica, 59, 552-554.

Hassing, G. S. 1971. Inhibition of Corynebacterium acnes lipase by tetracycline. Journal of Investigative Dermatology, 56, 189-192.

Hoefrler, U., Ko, H. L. AND PUlvereR, G. 1976. Antimicrobial susceptibility of Propionibacterium acnes and related microbial species. Antimicrobial Agents and Chemotherapy, 10, 387-394.

Hoeffler, U., Niederau, W. AND Pulverer, G. 1980. Susceptibility of cutaneous propionibacteria to newer antibiotics. Chemotherapy, 26, 7-11.

Holdeman, L. V. AND MoORE, W. E. C. 1972. Anaerobe laboratory manual. Virginia Polytechnic Institute and State University, Blacksburg, VA.

Holland, K. T., InGHam, E. AND CunlifFe, W. J. 1981. The microbiology of acne. Journal of Applied Bacteriology, 51, 195-215.

Lee, W. L., Shalita, A. R., Suntharalingam, K. and Fikrig, S. M. 1982. Neutrophil chemotaxis by Propionibacterium acnes lipase and its inhibition. Infection and Immunity, 35, 71-78.

LeYDEN, J. J. 1976. Antibiotic resistant acne. Cutis, 17, 593-596.

Leyden, J. J., McGinley, K. J. AND Kligman, A. M. 1982. Tetracycline and minocycline treatment. Effects on skin-surface lipid levels and Propionibacterium acnes. Archives of Dermatology, 118, 19-22. 
Marples, R. R. and Kligman, A. M. 1971. Ecological effects of oral antibiotics on the microflora of human skin. Archives of Dermatology, 103, 148-153.

Marples, R. R., Downing, D. T. and Kligman, A. M. 1971. Control of free fatty acids in human surface lipids by Corynebacterium acnes. Journal of Investigative Dermatology, 56, $127-131$.

Martin, W. J., Gardner, M. and Washington, J. A. 1972. In vitro antimicrobial susceptibility of anaerobic bacteria isolated from clinical specimens. Antimicrobial Agents and Chemotherapy, 1, 148-158.

Milstone, E. B., McDonald, A. J. and Scholhamer, C. F. 1981. Pseudomembranous colitis after topical application of clindamycin. Archives of Dermatology, 117, 154-155.

Noble, W. C. 1981. Choice of topical antibiotic-a microbiological viewpoint. Clinical and Experimental Dermatology, 6, 503-507.

Puhvel, S. M. AND SAKamoto, M. 1977. A re-evaluation of fatty acids as inflammatory agents in acne. Journal of Investigative Dermatology, 68, 93-97.

Punvel, S. M. AND SaKamoto, M. 1980. Cytotaxin production by comedonal bacteria (Propionibacterium acnes, Propionibacterium granulosum and Staphylococcus epidermidis). Journal of Investigative Dermatology, 74, 36-39.

RASHLEIGH, P. L., RIFE, E. AND GoLTz, R. W. 1967. Tetracycline levels in skin surface film after oral administration of tetracycline to normal adults and to patients with acne vulgaris. Journal of Investigative Dermatology, 49, 611-615.

Resh, W. AND Stoughton, R. B. 1976. Topically applied antibiotics in acne vulgaris. Clinical response and suppression of Corynebacterium acnes in open comedones. Archives of Dermatology, 112, 182-184.

SMITH, M. A. AND WATERWORTH, P. M. 1961. The bacteriology of acne vulgaris in relation to its treatment with antibiotics. British Journal of Dermatology, 73, 152-159.

Stoughton, R. B. 1979. Topical antibiotics for acne vulgaris. Current usage. Archives of Dermatology, 115, 486-489.

Tally, F. P., Jacobus, N. V., Bartlett, J. G. And Gorbach, S. L. 1975. Susceptibility of anaerobes to cefoxitin and other cephalosporins. Antimicrobial Agents and Chemotherapy, $7,128-132$.

UNKLES, S. E. AND Gemmell, C. G. 1982. Effect of clindamycin, erythromycin, lincomycin and tetracycline on growth and extracellular lipase production by propionibacteria in vitro. Antimicrobial Agents and Chemotherapy, 21, 39-43.

Wang, W. L. L., Everett, E. D., Johnson, M. and Dean, E. 1977. Susceptibility of Propionibacterium acnes to seventeen antibiotics. Antimicrobial Agents and Chemotherapy, 11, 171-173.

Weaber, K., Freedman, R. AND Eudy, W. W. 1971. Tetracycline inhibition of a lipase from Corynebacterium acnes. Applied Microbiology, 21, 639-642.

WeBster, G. F., MCGINLEY, K. J. AND LEYDEN, J. J. 1981. Inhibition of lipase production in Propionibacterium acnes by sub-minimal-inhibitory concentrations of tetracycline and erythromycin. British Journal of Dermatology, 104, 453-457.

WeEks, J. G., McCarty, L., Black, T. and Fulton, J. E. 1977. The inability of a bacterial lipase inhibitor to control acne vulgaris. Journal of Investigative Dermatology, 69, 236-243.

Williamson, P. AND Kligman, A. M. 1965. A new method for the quantitative investigation of cutaneous bacteria. Journal of Investigative Dermatology, 45, 498-503. 